EXHALED MARKERS

\title{
Exhaled nitric oxide predicts asthma relapse in children with clinical asthma remission
}

\author{
M W Pijnenburg, W Hofhuis, W C Hop, J C De Jongste
}

Thorax 2005;60:215-218. doi: 10.1136/thx.2004.023374

See end of article for authors' affiliations

......................

Correspondence to:

Dr Prof J C De Jongste,

Department of Paediatrics/

Paediatric Respiratory

Medicine, Erasmus

Medical Centre/Sophia

Children's Hospital,

P O Box 2060, 3000 CB

Rotterdam, The

Netherlands;

j.c.dejongste@

erasmusmc.nl

Received 17 February 2004 Accepted 30 August 2004

\begin{abstract}
Background: Nitric oxide in exhaled air $\left(\mathrm{FE}_{\mathrm{NO}}\right)$ is a marker of eosinophilic airway inflammation. A study was undertaken to determine whether $\mathrm{FE}_{\mathrm{NO}}$ predicts asthma relapse in asymptomatic asthmatic children in whom inhaled corticosteroids are discontinued.

Methods: Forty children (21 boys) of mean age 12.2 years on a median dose of $400 \mu \mathrm{g}$ budesonide or equivalent (range 100-400) were included. $\mathrm{FE}_{\mathrm{NO}}$ was measured before and 2, 4, 12, and 24 weeks after withdrawal of steroids. A relapse was defined as more than one exacerbation per month, or need for $\beta$ agonist treatment on 4 days per week for at least 2 weeks, or diurnal peak flow variability of $>20 \%$. $\mathrm{FE}_{\mathrm{NO}}$ measurements were performed online with an expiratory flow of $50 \mathrm{ml} / \mathrm{s}$.

Results: Nine patients relapsed. Two and 4 weeks after withdrawal of steroids geometric mean $\mathrm{FE}_{\mathrm{NO}}$ in children who were about to relapse was higher than in those who did not relapse: $35.3 \mathrm{ppb} v 15.7 \mathrm{ppb}$ at 2 weeks (ratio 2.3; $95 \% \mathrm{Cl} 1.2$ to $4.1 ; \mathrm{p}=0.01$ ) and $40.8 \mathrm{ppb} v 15.9 \mathrm{ppb}$ at 4 weeks (ratio $2.6 ; 95 \% \mathrm{Cl}$ 1.3 to 5.1). An $\mathrm{FE}_{\mathrm{NO}}$ value of $49 \mathrm{ppb}$ at 4 weeks after discontinuation of steroids had the best combination of sensitivity (71\%) and specificity (93\%) for asthma relapse.

Conclusion: $\mathrm{FE}_{\mathrm{NO}} 2$ and 4 weeks after discontinuation of steroids in asymptomatic asthmatic children may be an objective predictor of asthma relapse.
\end{abstract}

$\mathrm{R}$ emission of asthma is common in children. ${ }^{12}$ It is difficult to determine the time point at which to reduce or stop inhaled corticosteroids (ICS). ICS are currently adapted on clinical grounds with dose reduction based on patient history, sometimes influenced by parental or doctor's fears of side effects. However, there are few if any objective means to guide parents or children. According to current practice, ICS are discontinued in asthmatic children who are symptom-free for at least 6 months on a low dose of inhaled steroids. Follow up is discontinued soon after withdrawal of ICS. However, some of these children will have a relapse, and there is currently no objective parameter to predict the probability of asthma relapse following steroid withdrawal. Measurement of the fractional nitric oxide concentration in exhaled air $\left(\mathrm{FE}_{\mathrm{NO}}\right)$ has been proposed as a marker of eosinophilic airway inflammation. ${ }^{3}{ }^{4} \mathrm{FE}_{\mathrm{NO}}$ levels can be obtained easily and repeatedly with minimal discomfort to the patient, and measurement techniques have been well standardised. ${ }^{45}$ Treatment with ICS reduces FE $_{\mathrm{NO}}$ by a direct effect on transcription of inducible NO synthase and by reducing airway inflammation. ${ }^{6-8}$ Even low doses of ICS may decrease $\mathrm{FE}_{\mathrm{NO}}$ to normal levels. ${ }^{6-13}$ If $\mathrm{FE}_{\mathrm{NO}}$ could give additional information on the risk of asthma relapse, this could potentially modify current treatment strategies. Only a few studies have addressed the use of $\mathrm{FE}_{\mathrm{NO}}$ as a predictor of loss of asthma control related to changes in the ICS dose in adults, and the results are unequivocal. ${ }^{11}{ }^{14}{ }^{15}$ The aim of this study was to evaluate whether or not $\mathrm{FE}_{\mathrm{NO}}$ predicts the probability of asthma relapse in children in whom ICS are discontinued because of clinical remission.

\section{METHODS}

Forty children aged 6-18 years with asthma according to ATS criteria were enrolled at the moment when discontinuation of ICS was considered because of lack of symptoms for more than 6 months at a stable dose of ICS (100-400 $\mu \mathrm{g} /$ day budesonide or equivalent). Children on leukotriene receptor antagonists were excluded. Atopy was defined as RAST class
2 or higher for at least one airborne allergen. Written informed consent was obtained and the study was approved by the medical ethical committee of the Erasmus Medical Centre.

\section{Study design}

This prospective study lasted 26 weeks. During a run-in period of 2 weeks (from $t=-2$ to $t=0$ ) and 2 weeks before every visit, children recorded cough, wheezing, and dyspnoea twice daily on a 4 point scale (0-3) on a diary card as used in previous studies. ${ }^{16}$ The maximum possible cumulative symptom score was 252. Medication use and peak expiratory flow (PEF) were recorded twice daily. Children used a peak flow meter at home (Glaxo Wellcome, Zeist, The Netherlands) and recorded the personal best value of three attempts in the morning and evening. Diurnal PEF variability was defined as the difference between evening and morning values, divided by the mean of both measurements. At the start of the run-in period, the inhalation technique was checked and adherence to ICS treatment was strongly encouraged. Baseline $\mathrm{FE}_{\mathrm{NO}}$ was measured at $t=-2$ and $t=0$ weeks. Forced vital capacity (FVC) and forced expiratory volume in l second $\left(\mathrm{FEV}_{1}\right)$ before and after bronchodilation were measured at $t=-2,12$ and 24 weeks. At $t=0$ weeks, treatment with ICS was discontinued in patients with low symptom scores (below 14), mean PEF variability within $20 \%$, and not needing rescue medication. $\mathrm{FE}_{\mathrm{NO}}$ was monitored 2, 4, 12, and 24 weeks after withdrawal of ICS. The study design is shown in table 1 .

In cases in whom an upper respiratory tract infection occurred, follow up visits were postponed for 2 weeks. Patients were asked to contact the investigator if an exacerbation occurred, which was defined as asthma symptoms not responding to the bronchodilator. Subsequently,

Abbreviations: $\mathrm{FE}_{\mathrm{NO}}$, fractional nitric oxide concentration in exhaled air; $F_{E V}$, forced expiratory volume in 1 second; FVC, forced vital capacity; ICS, inhaled corticosteroid; PEF, peak expiratory flow 


\begin{tabular}{|c|c|c|c|c|c|c|}
\hline & \multicolumn{6}{|c|}{ Time (weeks) } \\
\hline & $t=-2$ & $t=0$ & $t=2$ & $t=4$ & $t=12$ & $t=24$ \\
\hline $\mathrm{FE}_{\mathrm{NO}}$ & $\times$ & $\times$ & $\times$ & $\times$ & $x$ & $x$ \\
\hline Diary card & & $\times$ & $\times$ & $x$ & $x$ & $x$ \\
\hline Spirometry & $x$ & & & & $\times$ & $x$ \\
\hline
\end{tabular}

children were seen and treated by their own paediatric pulmonologist, not the investigator. A relapse was defined as more than one exacerbation per month and/or exacerbations requiring oral or inhaled steroid use and/or need for rescue bronchodilators on 4 or more days per week for at least two consecutive weeks and/or mean diurnal PEF variability of $>20 \%$ according to the guidelines of the Dutch Paediatric Respiratory Group. ${ }^{17}$ The primary end point was relapse. At the point at which relapse occurred, children dropped out of the study.

\section{$\mathrm{FE}_{\text {NO }}$ measurements}

$\mathrm{FE}_{\mathrm{NO}}$ was measured online with an expiratory flow of $50 \mathrm{ml} / \mathrm{s}$ according to ATS and ERS guidelines. ${ }^{45} \mathrm{NO}$ was continuously sampled with a sampling flow of $175 \mathrm{ml} / \mathrm{min}$ and analysed by a chemiluminescence analyser (Sievers 280 NOA, Boulder, CO, USA). The analyser was calibrated weekly using 0 and 115 ppb NO certified gases (BOC, Herenthout, Belgium).

\section{Lung function testing}

Flow-volume curves were obtained with a dry rolling seal spirometer (Jaeger, Würzburg, Germany) according to ATS guidelines. After maximal inspiration, three reproducible loops with a maximum variability in FVC of $10 \%$ were obtained. FVC and $\mathrm{FEV}_{1}$ are expressed as percentage predicted..$^{18}$

\section{Statistical analysis}

$\mathrm{FE}_{\mathrm{NO}}$ values were logarithmically transformed before statistical analyses and the results expressed as geometric means. $\mathrm{FE}_{\mathrm{NO}}$ at $t=0$ weeks was used as baseline. For each interval between two measurements we assessed whether $\mathrm{FE}_{\mathrm{NO}}$ at the beginning of the interval was predictive for the occurrence of

Table 2 Baseline anthropometric and lung function data of study population ( $n=37$ children, 21 boys)

\begin{tabular}{|c|c|c|}
\hline & $\begin{array}{l}\text { Without relapse } \\
(\mathrm{n}=\mathbf{2 8})\end{array}$ & $\begin{array}{l}\text { With relapse } \\
(n=9)\end{array}$ \\
\hline Age (years) & $12.2(7.3-16.9)$ & $12.3(10.0-15.8)$ \\
\hline Atopy (n) & 21 & 8 \\
\hline Daily dose ICS & $400(100-400)$ & $200(100-400)$ \\
\hline $\begin{array}{l}\text { (budesonide equivalent) } \mu \mathrm{g} \\
\text { Height }(\mathrm{m})\end{array}$ & $1.53(1.30-1.81)$ & $1.52(1.44-1.66)$ \\
\hline Weight (kg) & $10.2(7.3-14.2)$ & $14.8(8.5-25.8)$ \\
\hline $\mathrm{FEV}_{1}(\%$ pred) & $100(73-134)$ & $99(88-109)$ \\
\hline FVC (\% pred) & $102(66-126)$ & $105(87-118)$ \\
\hline $\mathrm{FEV}_{1}$ (\% pred) post* & $106(80-139)$ & 107 (91-119) \\
\hline FVC (\% pred) post* & $103(66-127)$ & $105(78-118)$ \\
\hline PEF (I/s) & $383(195-600)$ & $426(270-800)$ \\
\hline PEF diurnal variabilty (\%) & $5.6(1-10)$ & $6.3(3-11)$ \\
\hline Baseline $\mathrm{FE}_{\mathrm{NO}}(\mathrm{ppb})$ & $10.5(7.3-14.2)$ & $14.8(8.5-25.8)$ \\
\hline
\end{tabular}

ICS, inhaled corticosteroid; $\mathrm{FEV}_{1}$, forced expiratory volume in 1 second; $\mathrm{FVC}$, forced vital capacity; $\mathrm{PEF}$, peak expiratory flow; $\mathrm{FE}_{\mathrm{NO}}$, fractional nitric oxide concentration in exhaled air.

Data are given as mean (range) except for the dose of ICS which is given as median. $\mathrm{FE}_{\mathrm{NO}}$ is given as geometric mean with $95 \%$ confidence interval. None of the items differed significantly between children with and without relapse.

${ }^{*}$ After bronchodilation with $1000 \mu \mathrm{g}$ terbutaline. relapse during the interval. Subsequently, the information from these four analyses were combined using conditional logistic regression which relates the probability of relapse in each period to $\mathrm{FE}_{\mathrm{NO}}$ at the start of this period. ${ }^{19}$ Multivariate analysis was repeated using either $\mathrm{FE}_{\mathrm{NO}}$ or the ratio of $\mathrm{FE}_{\mathrm{NO}}$ to baseline $\mathrm{FE}_{\mathrm{NO}}$. $\mathrm{FE}_{\mathrm{NO}}$ at baseline and at the various time points was compared in patients with and without clinical relapse using Mann-Whitney $\mathrm{U}$ tests. ROC curves for $\mathrm{FE}_{\mathrm{NO}} 2$ and 4 weeks after discontinuation of ICS were constructed. The correlation between $\mathrm{FE}_{\mathrm{NO}}$ and clinical and lung function parameters was assessed using Spearman's correlation coefficient.

\section{RESULTS}

Of the 40 children included in the study, one dropped out because of a high symptom score during the run-in period and two were lost to follow up. The remaining 37 patients (21 boys) had a mean age of 12.2 years (range 7.3-16.9). Data on the study population are shown in table 2 . Twenty nine were atopic; these children did not differ from non-atopic children in age, height and weight, nor in pulmonary function tests or baseline $\mathrm{FE}_{\mathrm{NO}}$. None of the children used long acting $\beta_{2}$ agonists or leukotriene antagonists.

Baseline geometric mean $\mathrm{FE}_{\mathrm{NO}}$ at $t=0$ was $11.2 \mathrm{ppb}(95 \%$ CI 8.5 to 15.3). This did not differ significantly from $\mathrm{FE}_{\mathrm{NO}}$ at $t=-2$, the start of the run-in period $(\mathrm{p}=0.67)$. Intraindividual variability between values at $t=-2$ and

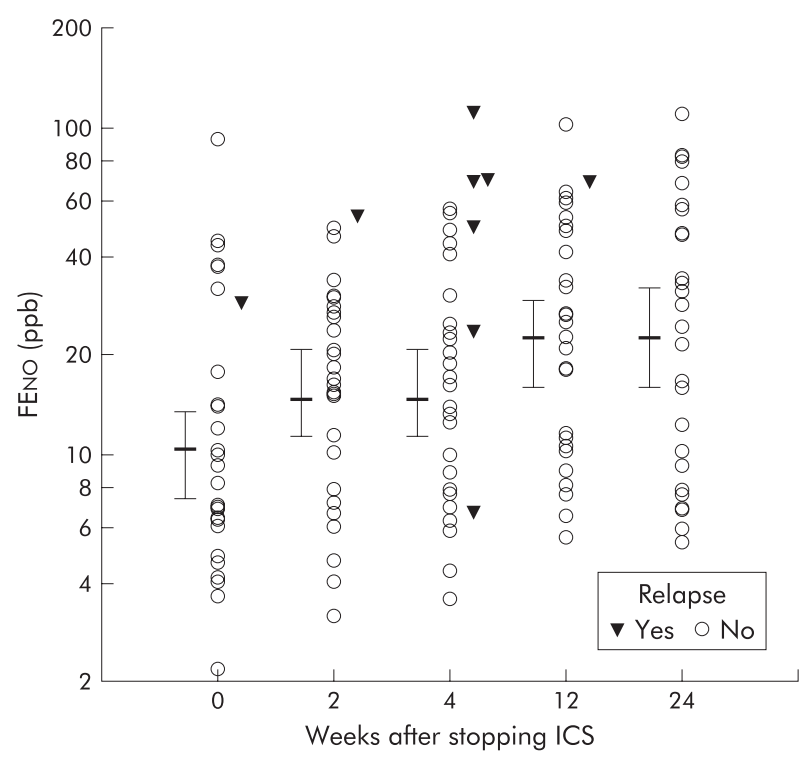

Figure $1 \mathrm{FE}_{\mathrm{NO}}$ values in patients with and without an asthma relapse. For each period $(0-2,2-4,4-12$, and 12-24 weeks) patients were classified according to whether they relapsed or not in the period indicated. $\mathrm{FE}_{\mathrm{NO}}$ values were obtained at the start of each period. For patients without a relapse geometric mean $\mathrm{FE}_{\mathrm{NO}}$ and $95 \%$ confidence intervals are given. The $x$ axis depicts number of weeks after withdrawal of ICS. One patient relapsed in the first period ( $0-2$ weeks), one between 2 and 4 weeks, six between 4 and 12 weeks, and one after 12 weeks. 
$t=0$ weeks was considerable (intraclass correlation coefficient 0.52).

\section{$\mathrm{FE}_{\mathrm{NO}}$ and relapse of asthma}

Nine patients $(24 \%)$, one of whom was non-atopic, had a clinical relapse after a median of 36 days (range 14-141). Of these nine patients, five had two exacerbations within 1 month or a single exacerbation requiring oral or inhaled steroids and four used their bronchodilator as rescue therapy for $\geqslant 4$ days a week during at least two consecutive weeks. Six children relapsed between 4 and 12 weeks after withdrawal of ICS; in the periods 0-2 weeks, 2-4 weeks, and 1224 weeks, one patient relapsed in each period (fig 1). Children who experienced an asthma relapse did not differ in baseline demographic or pulmonary function data (table 2). There was no difference in initial steroid dose of children who did or did not relapse (Mann-Whitney U test, $\mathrm{p}=0.28$ ), nor was there a significant difference in baseline geometric mean $\mathrm{FE}_{\mathrm{NO}}$ between the two groups of patients ( 14.8 ppb $v 10.5 \mathrm{ppb}$, respectively; ratio $1.4 ; 95 \%$ CI 0.7 to 2.8 , $\mathrm{p}=0.32)$. Two weeks after withdrawal of ICS the geometric mean $\mathrm{FE}_{\mathrm{NO}}$ in children who relapsed thereafter $(\mathrm{n}=8)$ was significantly higher than in those who did not relapse (35.3 ppb v $15.7 \mathrm{ppb}$; ratio 2.3 ; $95 \%$ CI 1.2 to $4.1, \mathrm{p}=0.01$ ). The same was true for $\mathrm{FE}_{\mathrm{NO}}$ after 4 weeks without steroids for the seven children who relapsed after 4 weeks ( $40.8 \mathrm{ppb}$ and $15.9 \mathrm{ppb}$; ratio 2.6 ; $95 \%$ CI 1.3 to $5.1, \mathrm{p}=0.009$; figl).

$\mathrm{FE}_{\mathrm{NO}}$ at 4 weeks after withdrawal of ICS predicted relapse in the forthcoming period (4-12 weeks after withdrawal, $\mathrm{p}=0.025)$. Multivariate logistic regression combining results of all periods showed that $\mathrm{FE}_{\mathrm{NO}}$ was a better predictor of asthma relapse $(p=0.001)$ than the $\mathrm{FE}_{\mathrm{NO}}$ ratio (actual $\mathrm{FE}_{\mathrm{NO}}$ divided by baseline $\left.\mathrm{FE}_{\mathrm{NO}}\right)(\mathrm{p}=0.04)$. For each doubling of $\mathrm{FE}_{\mathrm{NO}}$ the relapse rate increased by a factor 3.0 (95\% CI 1.5 to 7.1). The results were similar when only atopic patients were analysed.

Two patients were included who later admitted to having used more than $400 \mu \mathrm{g}$ budesonide regularly before enrolment. One of them relapsed. If both children were excluded, multivariate logistic regression still showed that $\mathrm{FE}_{\mathrm{NO}}$ predicted asthma relapse in the remainder $(p=0.003)$.

ROC curves indicated that a $\mathrm{FE}_{\mathrm{NO}}$ value of $49 \mathrm{ppb} 4$ weeks after stopping steroids had the best combination of sensitivity and specificity for predicting relapse (sensitivity: 71\% (95\% CI 29 to 96 ) and specificity $93 \%$ (95\% CI 76 to 99); fig 2). The positive and negative predictive values of $\mathrm{FE}_{\mathrm{NO}}$ of $49 \mathrm{ppb}$ were $71 \%$ and $93 \%$, respectively.

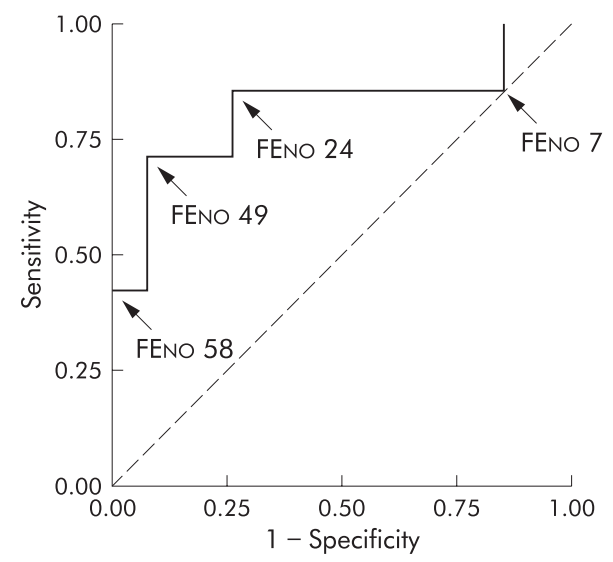

Figure 2 ROC curve for $\mathrm{FE}_{\mathrm{NO}} 4$ weeks after discontinuation of inhaled corticosteroids. The optimal combination of sensitivity and specificity for identifying children with relapse was for $\mathrm{FE}_{\mathrm{NO}} 49 \mathrm{ppb}(71 \%$ and $93 \%$, respectively).

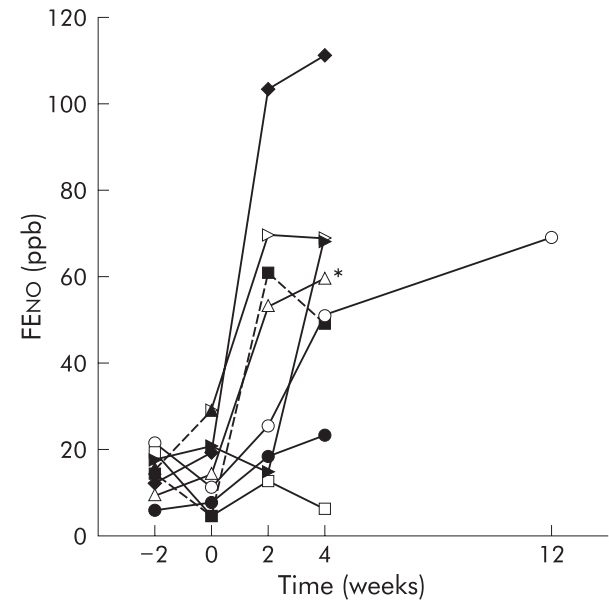

Figure 3 Course of $\mathrm{FE}_{\mathrm{NO}}$ values in nine patients who relapsed. The only non-atopic patient who experienced a relapse is marked with an asterisk.

The course of $\mathrm{FE}_{\mathrm{NO}}$ in all individuals who experienced a relapse is shown in fig 3 . In patients who did not relapse there was a general trend for $\mathrm{FE}_{\mathrm{NO}}$ to rise with time from a geometric mean of $10.2 \mathrm{ppb}$ at the start of the study to $22.2 \mathrm{ppb}$ after 26 weeks of follow up (fig 1). $\mathrm{FE}_{\mathrm{NO}}$ showed an overall tracking pattern in those who did not relapse.

\section{Correlations between $\mathrm{FE}_{\mathrm{NO}}$, clinical symptoms, and pulmonary function tests}

The results of pulmonary function tests, atopic state, PEF variability, cumulative symptom score and use of rescue medication during the run-in period did not differ between children with or without a relapse. Cumulative symptom scores, spirometric data, PEF values, and PEF variability did not correlate with geometric mean $\mathrm{FE}_{\mathrm{NO}}$ at any time point.

\section{Other parameters and relapse of asthma}

Symptom scores, peak flow, diurnal variability in peak flow, or other lung function tests performed during the run-in period did not predict asthma relapse.

\section{DISCUSSION}

We found that $\mathrm{FE}_{\mathrm{NO}}$ at 2 and 4 weeks after discontinuing ICS predicted asthma relapse in asthmatic children who were taken off ICS because of clinical remission. Initial $\mathrm{FE}_{\mathrm{NO}}$ levels measured while patients were still on ICS were not predictive of relapse. An $\mathrm{FE}_{\mathrm{NO}}$ of $49 \mathrm{ppb}$ or higher 4 weeks after discontinuation of ICS had the best combination of sensitivity $(71 \%)$ and specificity (93\%).

Few other studies have assessed $\mathrm{FE}_{\mathrm{NO}}$ longitudinally after discontinuation or reduction of ICS, and none of these included children. Our results are in agreement with the study by Jones et al ${ }^{11}$ in which adult asthmatics treated with a mean daily ICS dose of up to $1600 \mu \mathrm{g}$ were forced off steroids and followed for loss of asthma control. In this study, in contrast to ours, discontinuing steroids was not clinically indicated, and loss of control occurred earlier, after a median of 17 days. Their $\mathrm{FE}_{\mathrm{NO}}$ values were much lower, probably due to the higher flow rate of $250 \mathrm{ml} / \mathrm{s}$ used to obtain exhaled air samples. Lim et $a l^{14}$ performed a similar study in adults and their preliminary report states that NO in mixed nasal/oral exhaled air did not predict asthma relapse. However, mixed expired air is contaminated by high nasal levels of NO which makes interpretation impossible. Moreover, they defined relapse as a recurrence of asthma symptoms requiring either 
$\beta_{2}$ agonists or ICS. This might well explain any discrepancy between their findings and ours.

Jatakanon et $a l^{20}$ studied several non-invasive markers of airway inflammation in asthma exacerbations induced by forced reduction of ICS doses from more than $800 \mu \mathrm{g}$ to $200 \mu \mathrm{g}$ budesonide in adults. $\mathrm{FE}_{\mathrm{NO}}$ at baseline did not predict loss of asthma control. However, there was a rapid increase in $\mathrm{FE}_{\mathrm{NO}}$ before exacerbations 2-4 weeks after decreasing inhaled steroids. Only 15 patients were included in the study, and this small number could easily lead to nonsignificant findings. Furthermore, ICS were not completely withdrawn, which reduces the possibility of finding a difference between the groups.

The increases in $\mathrm{FE}_{\mathrm{NO}}$ over time in children who relapsed were consistent and larger than within-subject baseline fluctuations. However, the intra-individual variability in $\mathrm{FE}_{\mathrm{NO}}$ measurements at the beginning and end of our 2 week run-in period was quite high. Few data are available on long term within-subject reproducibility of $\mathrm{FE}_{\mathrm{NO}}$ in asthmatic children. Earlier reports have focused on short term reproducibility, which is excellent. Kharitonov et $a^{21}$ found intraclass correlation coefficients better than 0.90 in adults and children with and without asthma, with $95 \%$ limits of agreement of about $4 \mathrm{ppb}$ when children were tested repeatedly within 4 days. Jones et al reported a withinsubject coefficient of variation of $\mathrm{FE}_{\mathrm{NO}}$ measured with a l week interval of $10.5 \%{ }^{11}$ The variability in our study may be due to the long interval of 2 weeks between $\mathrm{FE}_{\mathrm{NO}}$ assessments. We also reasoned that inclusion in the study as such might affect $\mathrm{FE}_{\mathrm{NO}}$ because of better compliance with ICS during the run-in. This seems unlikely as increased compliance would lead to a reduction in $\mathrm{FE}_{\mathrm{NO}}$ whereas we found no significant difference between $\mathrm{FE}_{\mathrm{NO}}$ at $t=-2$ and $t=0$, with a trend towards higher levels at $t=0$. In addition, ambient NO levels can be a source of variability. However, we found no relation between ambient $\mathrm{NO}$ and $\mathrm{FE}_{\mathrm{NO}}$, so we think ambient NO levels do not explain the variability in $\mathrm{FE}_{\mathrm{NO}}$.

We included both atopic and non-atopic asthmatic subjects, reflecting the asthma population in daily practice. The numbers are too small for a subgroup analysis; only one non-atopic child relapsed. The patients who did not relapse without medication showed a wide range of $\mathrm{FE}_{\mathrm{NO}}$ values (fig 1). In these children no correlation was found between $\mathrm{FE}_{\mathrm{NO}}$ and symptom scores. As our follow up was 6 months, we cannot exclude that some of the children might relapse later. The possible clinical relevance of an increased $\mathrm{FE}_{\mathrm{NO}}$ in asymptomatic children therefore remains unclear.

What are the implications of these results for clinical practice? Our findings in this relatively small group of asthmatic children strongly suggest that $\mathrm{FE}_{\mathrm{NO}}$ measurements at 2 and 4 weeks after cessation of steroids are helpful for identifying children in whom relapse of asthma is more likely to occur and who might benefit from a close follow up. However, patient numbers in this study are small and more children who did not relapse had raised $\mathrm{FE}_{\mathrm{NO}}$ levels than those who did relapse. Larger studies are needed to confirm the role of $\mathrm{FE}_{\mathrm{NO}}$ in decision making on ICS in asthmatic children and to calculate more accurately the sensitivity and specificity of different cut-off levels of $\mathrm{FE}_{\mathrm{NO}}$.
In conclusion, this is the first study in children showing that $\mathrm{FE}_{\mathrm{NO}}$ is an early predicting marker of relapse in asthma after cessation of ICS. Larger studies are now warranted to substantiate this finding to further define the role of $\mathrm{FE}_{\mathrm{NO}}$ in this aspect of asthma management.

\section{Authors' affiliations}

M W Pijnenburg, W Hofhuis, J C De Jongste, Department of

Paediatrics/Paediatric Respiratory Medicine, Erasmus Medical Centre/ Sophia Children's Hospital, Rotterdam, The Netherlands

W C Hop, Department of Biostatistics and Epidemiology, Erasmus

Medical Centre/Sophia Children's Hospital, Rotterdam, The

Netherlands

MWP was supported by a research grant from the Dutch Asthma Foundation and WH was supported by an unrestricted grant from Glaxo Smith Kline, The Netherlands.

\section{REFERENCES}

1 Strachan DP. The epidemiology of childhood asthma. Allergy 1999;54:7-11.

2 Barbee RA, Murphy S. The natural history of asthma. J Allergy Clin Immunol 1998; 102:S65-72.

3 Kharitonov SA, Barnes PJ. Exhaled markers of pulmonary disease. Am J Respir Crit Care Med 2001;163:1693-722.

4 Baraldi E, De Jongste JC on behalf of the task force. ERS/ATS statement. Measurement of exhaled nitric oxide in children. Eur Respir $J$ 2002;20:223-37.

5 American Thoracic Society. Recommendations for standardised procedures for the online and offline measurement of exhaled lower respiratory nitric oxide and nasal nitric oxide in adults and children-1999. Am J Respir Crit Care Med 1999;160:2104-17.

6 Jatakanon A, Kharitonov SA, Lim S, et al. Effect of differing doses of inhaled budesonide on markers of airway inflammation in patients with mild asthma. Thorax 1999;54:108-14.

7 Baraldi E, Azzolin NM, Zanconato S, et al. Corticosteroids decrease exhaled nitric oxide in children with acute asthma. J Pediatr 1997;131:381-5.

8 Hamid Q, Springall DR, Riveros-Moreno V, et al. Induction of nitric oxide synthase in asthma. Lancet 1993;342:1510-3.

9 Kharitonov SA, Yates DH, Chung KF, et al. Changes in the dose of inhaled steroid affect exhaled nitric oxide levels in asthmatic patients. Eur Respir J 1996;9:196-201.

$10 \operatorname{Lim} \mathrm{S}$, Jatakanon A, John $M$, et al. Effect of inhaled budesonide on lung function and airway inflammation. Assessment by various inflammatory markers in mild asthma. Am J Respir Crit Care Med 1999;159:22-30.

11 Jones SL, Kittelson J, Cowan JO, et al. The predictive value of exhaled nitric oxide measurements in assessing changes in asthma control. Am J Respir Crit Care Med 2001; 164:738-43.

12 Silkoff PE, McClean P, Spino M, et al. Dose-response relationship and reproducibility of the fall in exhaled nitric oxide after inhaled beclomethasone dipropionate therapy in asthma patients. Chest 2001;119:1322-8.

13 Beck-Ripp J, Griese M, Arenz S, et al. Changes of exhaled nitric oxide during steroid treatment of childhood asthma. Eur Respir J 2002;19:1015-9.

14 Lim TK, Ngerng WJ, Phillip R, et al. Exhaled nitric oxide levels did not predict asthma relapse during the discontinuation of inhaled corticosteroid therapy. Am J Respir Crit Care Med 2001;163:A48.

15 Leuppi JD, Salome CM, Jenkins CR, et al. Predictive markers of asthma exacerbation during stepwise dose reduction of inhaled corticosteroids. Am J Respir Crit Care Med 2001;163:406-12

16 Verberne AA, Frost C, Duiverman EJ, et al. Addition of salmeterol versus doubling the dose of beclomethasone in children with asthma. Am J Respir Crit Care Med 1998; 158:213-9.

17 Hoekstra MO. Treatment of asthma in children; revised guidelines from paediatric pneumologists. Ned Tijdschr Geneesk 1997; 141:2223-9.

18 Zapletal AS, Samanek M, Paul T. Lung function in children and adolescents. Methods, reference values. In: Herzog H, ed. Progress in respiration research, Volume 22. Basel: Karger, 1987:114-218.

19 Cox DR. Regression models and life-tables. J R Stat Soc B 1972;34:187-220.

20 Jatakanon A, Lim S, Barnes PJ. Changes in sputum eosinophils predict loss of asthma control. Am J Respir Crit Care Med 2000;161:64-72.

21 Kharitonov SA, Gonio F, Kelly C, et al. Reproducibility of exhaled nitric oxide measurements in healthy and asthmatic adults and children. Eur Respir J 2003;21:433-8. 